\title{
Effect of Prostatic Fluid and Different Cryoprotectants on post-thaw Dog Spermatozoa
}

\author{
Kaushal Kusum ${ }^{\text {** }}$, Harendra Kumar Gupta ${ }^{2}$, Ramakrishna Roy ${ }^{3}$, \\ Raghavendra Prasad Mishra ${ }^{4}$ and Saurabh ${ }^{5}$
}

\author{
${ }^{1}$ Department of Veterinary Gynaecology and Obstetrics, Apollo College of Veterinary \\ Medicine, Jaipur, India \\ ${ }^{2}$ Division of Animal Reproduction, ICAR-Indian Veterinary Research Institute (IVRI), \\ Izzatnagar, Bareilly-243122, India \\ ${ }^{3}$ Krishi Vigyan Kendra, Sipaya, Gopalganj, Bihar (Dr. Rajendra Prasad Central Agricultural \\ University), India \\ ${ }^{4}$ Department of Veterinary Public Health, ${ }^{5}$ Department of Livestock Farm Complex, Apollo \\ College of Veterinary Medicine, Jaipur, India \\ *Corresponding author
}

\section{A B S T R A C T}

\begin{tabular}{l}
\hline Ke y w o r d s \\
Dog, Prostatic fluid, \\
$\begin{array}{l}\text { Cryoprotectants, } \\
\text { Post-thaw, Motility, } \\
\text { Viability, HOSST, } \\
\text { Acrosomal integrity }\end{array}$ \\
\hline Article Info \\
$\begin{array}{l}\text { Accepted: } \\
\text { 20 June } 2020 \\
\text { Available Online: } \\
10 \text { July } 2020\end{array}$ \\
\hline
\end{tabular}

Seminal plasma in dogs is prostatic in origin. Prostatic fluid plays role in immunological, motility and energy supply. Forty eight ejaculates of sperm rich fraction were collected from four adult male spitz dogs. Prostatic fluid was collected from the third fraction. Sperm rich semen was diluted (1:2) with Tris Fructose Egg Yolk Glycerol and divided into four cryoprotectant groups viz $8 \%$ Glycerol (Group I, control), 4 \% Glycerol (Group II), 5 $\%$ Ethylene Glycol (Group III) and $4 \%$ Glycerol+4\% Ethylene Glycol (Group IV), cryopreserved for $24 \mathrm{hrs}$ thereafter thawed and prostatic fluid added with the objective to study motility, viability, abnormality, Hypo-osmotic swelling test (HOSST) and acrosomal integrity. Addition of prostatic fluid post thaw significantly increased motility compared to no addition of prostatic fluid in all cryoprotectants however other parameters such as livability, abnormality, HOSST and acrosomal integrity remained changed. Among the post thaw prostatic fluid added groups, Group III ( $5 \%$ Ethylene glycol) had significantly higher $(\mathrm{P}<0.01)$ motility, livability, Hypo-osmotic swelling Test (HOSST) and acrosomal integrity whereas significantly lower $(\mathrm{P}<0.01)$ in Group IV, abnormality as compared to Group I, control (8\% Glycerol). The other cryoprotectants Group II (4\% Glycerol) and Group III (4 \% Glycerol + 4 \% Ethylene Glycol) performed higher in Group IV.

\section{Introduction}

Prostate is the only accessory gland of the uro-genital tract of the dog and prostatic fluid is the only component of the seminal plasma (England et al., 1990). During mating, sperm rich second fraction is followed by large volume of the third fraction which is prostatic 
in origin. The prostatic secretion contains electrolytes (Sodium, Potassium, Chloride, Phosphate, Magnesium) trace minerals, bicarbonate, fructose and lactic acid (Bartlett 1962, England et al., 1990) which provide energy and function as osmotic and $\mathrm{pH}$ buffers for spermatozoa.

The fertilizing ability of the spermatozoa depends on the motility necessary to reach the oocytes, sperm membrane integrity necessary to bind to the Zona pellucida of the oocyte and acrosomal integrity necessary to store the enzymes that are released to penetrate zona pellucida. Different in vitro studies with dilution of dog spermatozoa with prostatic fluid have shown a decrease in motility and a decline in the number of normal sperm cells after 2 hours of incubation at $37^{\circ} \mathrm{C}$ (England and Allen, 1992), a detrimental effect on semen preservation both after refrigeration at $4^{\circ} \mathrm{C}$ (Rota et al., 1995) and after refrigeration followed by freezing (Srivaidyapong et al., 2001). However, in vivo studies with either exposure of sperm to prostatic fluid before freezing (Hori et al, 2005) or dilution of frozen thawed semen with prostatic fluid (Nothling et al., 2005) resulted in higher fertility rates and improved conception. The present study was undertaken to study the effect of addition of prostatic fluid to frozen thawed cryopreserved (with different cryoprotectants) dog spermatozoa on semen quality parameters viz. motility, viability, abnormality, Hypo-osmotic swelling test (HOSST) and acrosomal integrity.

\section{Materials and Methods}

\section{Animals}

Four healthy Spitz adult male dogs were maintained on uniform balance diet and management practices in Kennels of Animal Nutrition Division, Indian Veterinary Research Institute Izanagar, Bareilly.

\section{Collection, dilution and cryopreservation of semen with cryoprotectants}

Semen was collected by digital manipulation at weekly intervals. (Linde-Forsberg, 1991). The pre-sperm, sperm rich and post-sperm fraction were collected separately in clear, graduated, sterile semen collection cups. The pre-sperm and post-sperm fractions were discarded while sperm rich second fraction was collected as one ejaculate. Forty eight good ejaculates (second fraction) were collected from these dogs i.e. twelve ejaculates from each male. Semen was diluted in Tris fructose egg yolk glycerol dilutor (Davis et al.,1963) with a dilution rate of 1:2.

This dilution rate would ensure a minimum sperm density of $100 \mathrm{millions} / \mathrm{ml}$ of diluted semen. The diluted semen was divided into four groups viz, 8\% glycerol (Group I, control), $4 \%$ glycerol (Group II), 5\% ethylene glycol (Group III), $4 \%$ glycerol $+4 \%$ ethylene glycol (Group IV).

Extended semen was filled in fresh medium straws and was equilibrated at $50 \mathrm{C}$ for a period of $4 \mathrm{hrs}$. After equilibration the straws were kept in liquid nitrogen vapour around 4$6 \mathrm{~cm}$ above the level of liquid nitrogen for 1015 minutes. Thereafter, the straws were plunged into liquid nitrogen in cryocan for storage (Christiansen, 1984).

\section{Collection and processing of prostatic fluid}

Third fraction of all ejaculates was collected in $15 \mathrm{ml}$ plastic tissue culture tubes. The prostatic fluid was centrifuged at 3000 $\mathrm{rev} / \mathrm{min}$ for 5 minutes and the supernatant was transferred to one or more $15 \mathrm{ml}$ tissue culture tubes. The tubes were labelled with the name of the donor and date of collection and stored in domestic deep freeze at $-20 \mathrm{oC}$ until needed. 


\section{Evaluation of post thaw semen with prostatic fluid}

The straws were thawed at $37 \mathrm{oC}$ for 1 minute, prostatic fluid added and thereafter evaluated for motility, livability, abnormality, Hypoosmotic Swelling Test (HOSST) and acrosomal integrity.

\section{Motility}

A drop of semen was kept on a clean, dry, pre-warmed glass slide, covered with a clean glass cover slip and examined under microscope to assess the percentage of progressive motile spermatozoa (Thomas et al., 1993).

\section{Livability}

The assessment for live spermatozoa was by Eosin and Nigrosin staining method (Hancock 1951). One drop of sperm rich fraction was placed on a clean, grease-free pre warmed glass slide and 4-5 drops of Eosin-Nigrosin was placed near the semen drop. By using a plain fine glass rod, the stain and semen were mixed gently. After a minute a thin smear was made on a glass slide and dried in air. The dried smear was examined under oil immersion objective $(100 \mathrm{X})$ of phase contrast microscope. A total number of 200 sperms were counted. The sperm showing pink colour was considered as dead and the sperm which had not taken any stain was considered live. However, partly stain sperm were also considered dead.

\section{Abnormality \\ The abnormalities included micro, macro, pear shaped or detached in head region, swollen, abaxially attached, double or zig-zag mid piece in middle piece region and coupled tail over in tail region besides the proximal and distal droplets.}

\section{Hypo-osmotic Swelling Test (HOSST)}

To assess the membrane integrity hypoosmotic swelling test was done (England and Plummer, 1993) by mixing 150 milliosmol of $1 \mathrm{ml}$ hypo-osmotic solution in a test tube with $0.1 \mathrm{ml}$ of the semen and incubating the mixture for 30 minutes at $37 \mathrm{oC}$. After incubation the smears were prepared on glass slides. Dried smear were stained with three per cent Rose Bengal stain for 15 minutes (Tomar, 1970). The slides were then washed, air dried and a minimum of 200 spermatozoa were counted under microscope $(1000 \mathrm{X})$ to estimate the percentage of hypo-osmotically swelled spermatozoa. The spermatozoa were classified in 4 classes according to the presence of the following tail swelling pattern.

Pattern A : No swelling, no membrane reaction

Pattern B : $\quad$ Swelling of the tip of the tail

Pattern C : $\quad$ Different type of hairpin like swelling pattern or swelling of the mid piece.

Pattern D : : Complete swelling.

Cells displaying either pattern B, C or D were considered positive for the Hypo-osmotic swelling test.

\section{Acrosomal Integrity}

Acrosomal integrity was assessed by the method described by Watson, 1975 with modifications. The smears were made on clean, dry and grease-free glass slides and dried in air or warm thermostat plate $(37 \mathrm{oC})$. After drying, the slides were kept on a staining rack and smears were fixed with Hancock's fixative for $15 \mathrm{~min}$. Then the 
slides were decanted and Giemsa solution was poured directly over the smear and allowed to stain for $1 \mathrm{~min}$. Then the stain solution was poured out and the slides were rinsed in gentle flowing water, air dried and examined under oil immersion lens of microscope (100 $\mathrm{X})$. At least 100 sperms per slide were counted. The staining pattern and efficiency observed were equal to Watson's method which took two hours whereas this modified method took only 45 minutes.

\section{Statistical analysis}

Using the software available at Computer Section, IVRI, analysis of variance among the experimental treatment and comparison among means by Duncans multiple range test (DMRT) was carried out.

\section{Results and Discussion}

Addition of prostatic fluid post thaw significantly increased motility compared to no addition of prostatic fluid in all cryoprotectants however other parameters such as livability, abnormality, HOSST and acrosomal integrity remained changed.
(Table-1 and 2). (Nothling et al., 2007) Observed increased progressive motility with addition of Prostatic fluid post-thaw, (Milani et al., 2010) Found no positive effects on motility patterns post-thawing.(Rota et a., 2007) Incubated frozen thawed semen with autologous Prostatic fluid (PF) (1:2) for four hours at $38^{\circ} \mathrm{C}$ and found an initial reduction of hyperactive motility with PF treatment with effect on sperm longevity or acrosome status.(Dasetal.,2014).(Kusum et al., 2012). Motility is an important factor influencing fertility particularly the ability of the spermatozoa to reach the oocyte. Prostatic fluid is ejaculated into the vagina of the bitch after the sperm-rich fraction and coitus cannot be interrupted until the entire prostatic fluid fraction has been ejaculated. The seminal plasma in dogs is solely prostatic in origin (Bass et al., 1984). Many functions of seminal plasma have been reported such as immunological role (Sebastian et al., 1987) and motility modification (Setchell and Brooks, 1988). Intracellular ice crystals are formed during rapid cooling. Cells are killed by chemical toxicity or osmotic stress and by mechanical damage caused by phase separation of solution and crystals.

Table.1 Effect of prostatic fluid and different cryoprotectants on structural and functional change in post thaw dog spermatozoa (Mean $\pm \mathrm{SE} ; \mathrm{n}=12$ )

\begin{tabular}{|l|l|l|l|l|l|}
\hline S. No. & Parameters & \multicolumn{4}{|c|}{ Frozen Thawed spermatozoa } \\
\cline { 3 - 6 } & & Group I & Group II & Group III & Group IV \\
\hline $\mathbf{1}$ & $\begin{array}{l}\text { Progressive } \\
\text { motility (\%) }\end{array}$ & $29.25 \pm 1.54^{\mathrm{d}}$ & $34.58 \pm 1.95^{\mathrm{d}}$ & $38.92 \pm 1.35^{\mathrm{cd}}$ & $35.50 \pm 0.65^{\mathrm{C}}$ \\
\hline 2. & Livability (\%) & $51.92 \pm 1.15^{\mathrm{a}}$ & $54.17 \pm 1.29^{\mathrm{ab}}$ & $57.00 \pm 1.39^{\mathrm{b}}$ & $52.33 \pm 2.33^{\mathrm{b}}$ \\
\hline $\mathbf{3 .}$ & Abnormal (\%) & $28.58 \pm 0.70^{\mathrm{c}}$ & $27.33 \pm 1.00^{\mathrm{cd}}$ & $25.42 \pm 0.80^{\mathrm{c}}$ & $28.83 \pm 1.92^{\mathrm{d}}$ \\
\hline $\mathbf{4 .}$ & HOSST (\%) & $45.33 \pm 1.00^{\mathrm{cd}}$ & $48.75 \pm 0.98^{\mathrm{c}}$ & $51.50 \pm 1.00^{\mathrm{cd}}$ & $47.33 \pm 1.92^{\mathrm{b}}$ \\
\hline $\mathbf{5 .}$ & $\begin{array}{l}\text { Acrosomal } \\
\text { integrity (\%) }\end{array}$ & $58.08 \pm 0.91^{\mathrm{c}}$ & $57.25 \pm 1.15^{\mathrm{ab}}$ & $58.83 \pm 1.15^{\text {ab }}$ & $56.17 \pm 1.47^{\mathrm{c}}$ \\
\hline
\end{tabular}

Figures showing different superscript in a row differ significantly $((\mathrm{P} \leq 0.01)$.

Group I : $8 \%$ glycerol (control); Group II : $4 \%$ glycerol; Group III : $5 \%$ ethylene glycol; Group IV : $4 \%$ glycerol + $4 \%$ ethylene glycol. 
Table.2 Effect of different cryoprotectants on physiomorphological and functional parameters of spermatozoa in pooled and post thaw-dog semen

\begin{tabular}{|c|c|c|c|c|c|c|}
\hline \multirow[t]{2}{*}{ S.No } & \multirow{2}{*}{$\begin{array}{l}\text { Parameters } \\
\text { (in Percent) }\end{array}$} & \multirow{2}{*}{$\begin{array}{l}\text { Fresh } \\
\text { pooled } \\
\text { semen }\end{array}$} & \multicolumn{4}{|c|}{ Frozen Thawed Spermatozoa } \\
\hline & & & $\begin{array}{l}\text { Group I } \\
\text { (control) }\end{array}$ & Group II & Group III & Group IV \\
\hline 1 & $\begin{array}{l}\text { Progressive } \\
\text { motility }\end{array}$ & $62.75 \pm 0.65^{\mathrm{e}}$ & $26.50 \pm 0.81^{\mathrm{a}}$ & $34.25 \pm 0.95^{\mathrm{c}}$ & $36.83 \pm 0.73^{\mathrm{d}}$ & $29.25 \pm 0.94^{b}$ \\
\hline 2. & Livability & $75.00 \pm 0.72^{c}$ & $51.92 \pm 1.14^{\mathrm{a}}$ & $52.33 \pm 2.32^{b}$ & $\underset{b}{59.50 \pm 0.78}$ & $56.83 \pm 0.83^{b}$ \\
\hline 3 & Abnormal & $13.67 \pm 0.72^{a}$ & $28.58 \pm 0.70^{b c}$ & $28.83 \pm 1.90^{c}$ & $\underset{\mathrm{b}}{25.27 \pm 0.89}$ & $27.33 \pm 1.05^{b c}$ \\
\hline 4 & HOSST & $71.17 \pm 0.75^{c}$ & $46.17 \pm 1.34^{\mathrm{a}}$ & $47.33 \pm 1.92^{a}$ & $\underset{b}{51.83 \pm 1.06}$ & $47.83 \pm 2.00^{b}$ \\
\hline 5. & $\begin{array}{l}\text { Acrosomal } \\
\text { integrity }\end{array}$ & $78.92 \pm 0.91^{d}$ & $54.67 \pm 1.00^{\mathrm{a}}$ & $56.17 \pm 1.47^{\mathrm{ab}}$ & $61.17 \pm 1.18^{\mathrm{c}}$ & $58.33 \pm 1.15^{b}$ \\
\hline
\end{tabular}

NB : Figures showing different superscript in a row significantly different $(\mathrm{P} \leq 0.01)$.

Group I : 8\% glycerol (control); Group II : 4\% glycerol; Group III : 5\% ethylene glycol; Group IV : 4\% glycerol + $4 \%$ ethylene glycol

Among all the cryoprotectants Group III (5\% Ethylene glycol) had significantly higher $(\mathrm{P} \leq 0.01)$ motility, livability, Hypo-osmotic swelling Test (HOSST) and acrosomal integrity whereas significantly lower $(\mathrm{P} \leq 0.01)$ abnormality as compared to Group I (control, $8 \%$ Glycerol). The other cryoprotectants Group II (4\% Glycerol) and Group III (4\% Glycerol $+4 \%$ Ethylene Glycol) performed higher abnormality in Group IV(Table 1). Ethylene glycol has smaller molecular weight, a characteristic that may result in lower toxicity and higher permeability to cell (Massip, 2001). Ethylene glycol minimizes the detrimental effect of the dehydration and rehydration during the freezing and thawing processes (Pantano et al., 2000). Spermatozoa had a higher osmotic tolerance to quick addition and removal of ethylene glycol than glycerol. Dog sperm volume response to osmotic shock is regulated by the activity of potassium channel and is minimized by the presence of an intact cytoskeleton. Ethylene glycol might affect the functionality of potassium channel, their activation mechanism of fluxes of ions and organic osmolytes. The combination of 4 percent ethylene glycol and $4 \%$ glycerol maintain sperm motility, viability and acrosomal integrity (Bessa et al., 2006).

In conclusion addition of prostatic fluid post thaw significantly increased motility compared to no addition of prostatic fluid in all cryoprotectants however other parameters such as livability, abnormality, HOSST and acrosomal integrity remained changed. Five percent Ethylene glycol Group III had significantly higher $(\mathrm{P} \leq 0.01)$ motility, livability, Hypo-osmotic swelling Test (HOSST) and acrosomal integrity.

\section{Acknowledgements}

Author solemnly acknowledges the Animal Husbandry Department, Patna, Govt. of Bihar for necessary permission to pursue doctoral research on canine reproduction. I am thankful to ICAR-Indian Veterinary Research Institute, Izatnagar for providing financial assistance in the shape of Institute Senior Research Fellowship. 


\section{References}

Bartlett, D.J. 1962 Studies on the dog semen II. Biochemical characteristics. Journal of Reproduction and Fertility3: 190-205.

Bass, J.W., Molan, P.C. and Shamnon, P. 1983. Factor in seminal plasma of bulls that affect the viability and motility of spermatozoa. Journal of Reproduction and Fertility68: 275280.

Bessa, A.M., Rocha, A., and Aguirre, A.M. 2006. Comprising ethylene glycol with glycerol for cryopreservation of canine semen in egg-yolk tris extenders. Theriogenology., 66(9): 2047-2055.

Christiansen, I. J. 1984. Reproduction in dog and Cat. Baillier Tindal. pp 115-123.

Das, A., Biswas, R.K., Deka, B.C., and Dutta, J. 2018. Quality of LabradorRetriever dog semen on short-term preservation in different extenders. Indian Journal of Animal Research2(52): 220-225

Davis, I.S., Bratton, R.W., and Foote, R.H. 1963. Livability of bovine spermatozoa at $5,-25$ and $-85^{\circ} \mathrm{C}$ in Tris buffered and citrate buffered yolk extenders. Journal of Dairy Science. 46: 333-336.

England, G.C., Allen,W.E., and Middleton, D. J. 1990. An investigation into the origin of the first fraction of the canine ejaculate. Research in Veterinary Science49: 66-70

England, G.C.W., and Allen, W.E. 1992. Factors affecting the viability of canine spermatozoa. II. Effects of seminal plasma and blood. Theriogenology37:373-81

England, G.C.W., and Plummer, J M. 1993. Hypo-osmotic swelling of dog spermatozoa. Journal of Reproduction and Fertility (Suppl.). 47: 261-270.

Hancock, J.L. (1951). A staining technique for the study of the temperature shock in semen. Nature, 167: 323-324.

Hori, T., Hagiuda, K., Kawakami, E., and Tsutsui, T. 2005. Unilateral intrauterine insemination with prostatic fluid sensitized frozen caudal epididymal sperm in beagle dogs. Theriogenology63: 1573-1583.

Kusum, K., Ansari, M.R., and Roy, R.K. 2012. Effect of Cryoprotectants on Viability of canine spermatozoa. The Indian Veterinary journal89(10) : 1114.

Linde-Forsberg, C. 1991. Achieving canine pregnancy by using frozen or chilled extended semen. Veterinary Clinics of North America (Small Animal Practice) 21:467-485

Massip, A. 2001. Cryopreservation of embryo of farm animals. Reproduction in Domestic Animals.36: 49-55.

Milani, C., Fontbonne, A., Sellem, E., Stelletta, C., Gerard, O., and Romagnoli, S. 2010. Effect of postthaw dilution with caffeine, pentoxifylline, 2' -deoxyadenosine and prostatic fluid on motility of frozen thawed dog semen. Theriogenology74: 153-164.

Nothling, J.O., Shuttleworth, R., Haas, D.K., Thompson, P.N. 2005. Homologous prostatic fluid added to the frozen thawed dog spermatozoa prior to intravaginal insemination of bitches resulted in better fertility than albumin free TALP. Theriogenology 64: 975991

Nothling, J.O., Gerber, D., Colenbrander, B., Dijkstra, M., Baker, T., and Cramer, D.K. 2007. The effect of homologous prostatic fluid on motility and morphology of dog epididymal spermatozoa extended and frozen in Biladyl with Equex STM paste of Andromed. Theriogenology67: 264275. 
Pantano, T., de Mello, M.R., Garcia, J.F., Lee Ho $\mathrm{L}$ and Visintin, JA. 2000. Effect of cryoprotectant and plunging temperature in liquid nitrogen on the in vitro and in vivo development of murine morulae. Brazilian Journal of Veterinary Research and Animal Science, 37: 1413-1424.

Rota, A., Storm, B., and Linde, F.C. 1995. Effects of seminal plasma and three extenders on canine semen stored at 4 ${ }^{\circ}$ C. Theriogenology44:885-900.

Sebastian, S.M., Selvaraj, S., Aruldhas, M.M., and Govindarajulu, P. 1987. Pattern of neutral and phospholipids and the semen of normospermic oligospermic and Azoospermic men. Journal of Reproduction and Fertility79: 373-378

Setchell, B.P., and Brooks, D.E. 1988. Anatomy, vasculature, innervation and fluids of the male reproductive tract In: The physiology of Reproduction (Ed. Knobil. E, Neil J D) Raven Press ,
New York, USA pp 753-836.

Srivaidyapong, S., Ursem, P., and Colenbrander, B. 2001. Effect of prostatic fluid on motility, viability and acrosomal integrity of chilled and frozen thawed dog spermatozoa. Journal of Reproduction and Fertility.57 (Suppl) :383-386.

Thomas, P.G.A, Larsen, R.E., Burns, J.M., and Hahn, C.N. 1993. A comparison of three packaging techniques using two extenders for the cryopreservation of canine semen. Theriogenology 40: 1199-1205.

Tomar, N.S. 1970. Artificial insemination and reproduction of cattle and buffalo. Saroj Prakashan, Allahabad, India.

Watson, P.F. 1975. Use of giemsa stain to detect changes in acrosomes of deep frozen ram spermatozoa. Veterinary Record 97: 12-15.

\section{How to cite this article:}

Kaushal Kusum, Harendra Kumar Gupta, Ramakrishna Roy, Raghavendra Prasad Mishra and Saurabh. 2020. Effect of Prostatic Fluid and Different Cryoprotectants on post-thaw Dog Spermatozoa Int.J.Curr.Microbiol.App.Sci. 9(07): 2252-2258. doi: https://doi.org/10.20546/ijcmas.2020.907.262 